\title{
Intercomparison of ammonia measurement techniques at an intensively managed grassland site (Oensingen, Switzerland)
}

\author{
M. Norman ${ }^{1, *}$, C. Spirig ${ }^{2}$, V. Wolff ${ }^{3}$, I. Trebs ${ }^{3}$, C. Flechard $^{2,{ }^{* *}}$, A. Wisthaler ${ }^{1}$, R. Schnitzhofer ${ }^{1}$, A. Hansel ${ }^{1}$, and \\ A. Neftel $^{2}$ \\ ${ }^{1}$ Institute for Ion Physics and Applied Physics, University of Innsbruck, Innsbruck, Austria \\ ${ }^{2}$ Agroscope Reckenholz Tänikon Research Station (ART), Zürich, Switzerland \\ ${ }^{3}$ Max Planck Institute for Chemistry, Biogeochemistry Department, Mainz, Germany \\ *now at: Environment and Health Administration, Stockholm City, Sweden \\ ** now at: Institut National de la Recherche Agronomique (INRA), Rennes, France
}

Received: 2 September 2008 - Published in Atmos. Chem. Phys. Discuss.: 19 November 2008

Revised: 2 April 2009 - Accepted: 2 April 2009 - Published: 16 April 2009

\begin{abstract}
As part of a field campaign in the framework of the NitroEurope project, three different instruments for atmospheric ammonia $\left(\mathrm{NH}_{3}\right)$ measurements were operated sideby-side on a managed grassland site in Switzerland: a modified Proton Transfer Reaction Mass Spectrometer (PTRMS), a GRadient of AErosol and Gases Online Registrator (GRAEGOR), and an Automated Ammonia Analyzer (AiRRmonia). The modified PTR-MS approach is based on chemical ionization of $\mathrm{NH}_{3}$ using $\mathrm{O}_{2}^{+}$instead of $\mathrm{H}_{3} \mathrm{O}^{+}$as ionizing agent, GRAEGOR and AiRRmonia measure $\mathrm{NH}_{4}^{+}$ in liquids after absorption of gaseous $\mathrm{NH}_{3}$ in a rotating wetannular denuder and through a gas permeable membrane, respectively. Bivariate regression slopes using uncorrected data from all three instruments ranged from 0.78 to 0.97 while measuring ambient $\mathrm{NH}_{3}$ levels between 2 and $25 \mathrm{ppbv}$ during a 5 days intercomparison period. Correlation coefficients $r^{2}$ were in the range of 0.79 to 0.94 for hourly average mixing ratios. Observed discrepancies could be partly attributed to temperature effects on the GRAEGOR calibration. Bivariate regression slopes using corrected data were $>0.92$ with offsets ranging from 0.22 to $0.58 \mathrm{ppbv}$. The intercomparison demonstrated the potential of PTR-MS to resolve short-time $\mathrm{NH}_{3}$ fluctuations which could not be measured by the two other slow-response instruments. During conditions favoring condensation in inlet lines, the PTR-MS underestimated $\mathrm{NH}_{3}$ mixing ratios, underlining the importance of careful inlet designs as an essential component for any inlet-based instrument.
\end{abstract}

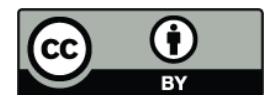

Correspondence to: M. Norman (michael.norman@slb.nu)

\section{Introduction}

As the most dominant gas phase base in the atmosphere ammonia $\left(\mathrm{NH}_{3}\right)$ plays a key role for the neutralization of acidic gases and aerosol particles (Asman et al., 1998). The uptake of $\mathrm{NH}_{3}$ on aerosol particles influences the aerosol chemical composition (Wells et al., 1998) and controls the acidity and nitrification of precipitation (Charlson and Rodhe, 1982; Dentener and Crutzen, 1994). $\mathrm{NH}_{3}$ is emitted in large quantities both from natural and anthropogenic sources (Bouwman et al., 1997). The natural sources include emission from soils, oceans, vegetation and living organisms. $\mathrm{NH}_{3}$ is known to be both emitted from and deposited to vegetation and it has positive effects on plants at low concentration, while it is harmful at higher concentrations (Fangmeier et al., 1994). However, large uncertainties still exist about the concentrations, surface-atmosphere exchange fluxes and cycling of atmospheric $\mathrm{NH}_{3}$. One major uncertainty is the uptake and/or emission rate from plants and soils. Much of this uncertainty is due to the relative scarcity of direct flux measurements, which in turn mainly has been due to the lack of reliable measurement techniques that can be operated automatically and with high time-resolution in the field.

One major difficulty for the development of measuring techniques for atmospheric $\mathrm{NH}_{3}$ is the simultaneous presence of $\mathrm{NH}_{x}$ in the gaseous, the particulate (e.g., ammonium nitrate) and the liquid phase $\left(\mathrm{NH}_{4}^{+}(\mathrm{aq})\right.$ in clouds and fog). The partitioning between these phases strongly depends on environmental factors, such as temperature and relative humidity (Mozurkewich, 1993). Another difficulty is the interaction of $\mathrm{NH}_{3}$ with the surface of many materials as well as its high water-solubility, thus making measurements

Published by Copernicus Publications on behalf of the European Geosciences Union. 
with any kind of inlet a challenge (Parrish and Fehsenfeld, 2000; Yokelson et al., 2003). These problems have caused the progress in the development of $\mathrm{NH}_{3}$ measurement techniques to be slower than for many other atmospheric compounds. The denuder technique is nowadays the most widely applied sampling technique for $\mathrm{NH}_{3}$ (Ferm, 1979). However, major limitations of the denuder technique are a relatively low time-resolution (minutes to hours) and the need for subsequent wet-chemical analysis, which may introduce errors due to sample storage and/or contamination problems when applied for in-situ measurements. Until the last decade most automatic atmospheric $\mathrm{NH}_{3}$ measurements with sufficiently low detection limits were based on wet chemistry, like for example the AMANDA technique (Ammonia Measurement by Annular Denuder sampling with on-line Analysis; Wyers et al., 1993; Erisman et al., 2001), and the DS-FIA (diffusion scrubber flow injection analyzer; Genfa et al., 1989; Dasgupta 1993). More recent developments of fast response techniques with low detection limits include for example Differential Optical Absorption Spectroscopy (DOAS, Gall et al., 1991), Photoacoustic Spectroscopy (Pushkarsky et al., 2002), Tuneable Diode Laser Absorption Spectroscopy (TDLAS, Warland et al., 2001) and Chemical Ionization Mass Spectrometry (CIMS, Nowak et al., 2007).

Several attempts have been made to compare different $\mathrm{NH}_{3}$ measurement techniques. An intercomparison by Wiebe et al. (1990) tested four measurements techniques for $\mathrm{NH}_{3}$ by filter packs, transition-flow reactors, simple and annular denuders and Fourier-Transform Infrared-Spectroscopy. Williams et al. (1992) compared five different $\mathrm{NH}_{3}$ measurement techniques including a photofragmentation/laser-induced fluorescence instrument (PF/LIF), a molybdenum oxide annular denuder sampling/chemiluminescence detection technique (MOADS), a tungsten oxide denuder sampling/chemiluminescence detection system (DARE), a citric acid coated denuder sampling/ion chromatographic analysis method (CAD/IC) and an oxalic acid coated filter pack sampling/colorimetric analysis method (FP/COL). A detailed study for determining the suitability of measuring techniques for air quality monitoring in the Netherlands is presented by Mennen et al. (1996). The study included seven methods, a wet-annular rotating denuder (WRD or WAD), a $\mathrm{WO}_{3}$-coated thermodenuder, a $\mathrm{V}_{2} \mathrm{O}_{5}$-coated thermodenuder, a DOAS system, a photoacoustic monitor and a chemiluminescence $\mathrm{NO}_{\mathrm{x}}$ monitor with $\mathrm{NH}_{3}$ converter. A field intercomparison was performed by Milford et al. (2000) during the ACE-2 experiment in Tenerife and included the AMANDA and the DS-FIA. The informal intercomparison reported by Fehsenfeld et al. (2002) compared a first version of the CIMS for $\mathrm{NH}_{3}$ measurements with conventional methods like the citric acid denuder and the Molybdenum oxide $\left(\mathrm{MoO}_{\mathrm{x}}\right)$ converter difference method. CIMS techniques for $\mathrm{NH}_{3}$ measurements were further tested by Nowak et al. (2006) who compared two different CIMS instruments, the NOAA Chemical Sci- ence Division (NOAA-CSD) apparatus and the Georgia Tech (GT) low pressure tube flow reactor, in the field. An ambitious laboratory test of six different techniques is presented in the study by Schwab et al. (2007). The study included the TDLAS, the wet-scrubbing long-path absorption photometer (LOPAP), the wet effusive diffusion denuder (WEDD), the ion mobility spectrometer (IMS), the Nitrolux laser acoustooptical absorption analyzer as well as a modified chemiluminescence analyzer. A recent study compared the performance of a quantum cascade laser spectrometer (QCLAS), a TDLAS and an AMANDA system both for concentration and flux measurements of ammonia (Whitehead et al., 2008).

The intercomparison presented here was performed within the framework of NitroEurope (NEU, www.nitroeurope.eu). One of the main NEU objectives is to establish robust datasets of land/atmosphere exchange fluxes of nitrogen and to study their impact on greenhouse gas budgets for representative European ecosystems. In line with this objective, $\mathrm{NH}_{3}$ was measured over an intensively managed grassland site at Oensingen, Switzerland, during July and August 2006. One of the main goals was to determine the drivers of surfaceatmosphere exchange fluxes of $\mathrm{NH}_{3}$ in grassland in relation to meteorological conditions and management practices, including fertilization and cutting. Three different instruments were compared for measurements of atmospheric $\mathrm{NH}_{3}$ : (a) an Automated Ammonia Analyzer AiRRmonia ${ }^{\mathrm{TM}}$ instrument (Mechatronics BV, Hoorn, The Netherlands) (Erisman et al., 2001), (b) the GRadient of AErosol and Gases Online Registrator (GRAEGOR) (Thomas et al., 2009) and (c) a modified proton transfer reaction mass spectrometer (PTRMS) (Norman et al., 2007). As far as we know, this is the first study to include these three systems. It describes results from the intercomparison, potential sources of error and the suitability of the different methods for in-situ measurements with a high temporal resolution.

\section{Experimental}

\subsection{Site description}

The field site was established in 2001 and is situated near the village of Oensingen in central Switzerland $\left(47^{\circ} 17^{\prime} \mathrm{N}\right.$, $07^{\circ} 44^{\prime} \mathrm{E}$ ) at about $450 \mathrm{~m}$ a.s.l. The site consists of two 50 x $150 \mathrm{~m}$ plots of grassland. One plot undergoes extensive management with no fertilizer application and 2-3 cuts per year and the second one is intensively managed with four fertilizer applications (150-200 $\mathrm{kg} \mathrm{N} \mathrm{ha}^{-1} \mathrm{y}^{-1}$ as ammonium nitrate and slurry) and 4-5 cuts per year (Ammann et al., 2004). The surrounding area is characterised by intensive agriculture, dominated by grasslands and arable crops. The prevailing climate at the site is temperate continental, with an average annual rainfall of about $1100 \mathrm{~mm}$ and a mean annual air temperature of $9^{\circ} \mathrm{C}$. 
The measurement site has been used for studies of carbon and greenhouse gas budgets within the EU-funded GREENGRASS and CarboEurope-IP programmes (Ammann et al., 2004; Flechard et al., 2005) and in ozone studies (Jäggi et al., 2006) as well as in nitrogen studies (Ammann et al., 2007; Neftel et al., 2007).

A trailer was placed on the border between the intensively managed plot and the extensive managed plot. The measurements in this paper were performed above the intensively managed plot. The PTR-MS instrument was placed inside the trailer. A $17 \mathrm{~m}$ long inlet tube extended out onto the field and was placed on a tripod. Both the AiRRmonia analyzer and the GRAEGOR were placed in the centre of the field. The maximum distance between the AiRRmonia instrument, the GRAEGOR and the tripod with the PTR-MS inlet was $5 \mathrm{~m}$. Furthermore, the prevailing wind directions parallel to the field orientation (Ammann et al., 2007) favoured minimal footprint differences for the three instruments.

The measurements presented in this paper were performed between the afternoon of 26th and midday on 31st of July 2006. This was the only period of the 2006 summer campaign when all three instruments were operated simultaneously. The latest fertilisation of the field prior to the measurement phase occurred on 13th of July by application of liquid cattle slurry.

\subsection{Measurements techniques}

\subsubsection{AiRRmonia}

The AiRRmonia analyzer was designed for long-term monitoring of gas-phase atmospheric $\mathrm{NH}_{3}$ and it is a further development of the AMANDA technique (Wyers et al., 1993; Erisman et al., 2001). The AiRRmonia has been employed in national $\mathrm{NH}_{3}$ monitoring networks e.g., in the Netherlands and in Denmark. Air is sampled via a $5 \mathrm{~cm}$ long PE (Polyethylene) tubing with $\mathrm{d}_{i}=0.17 \mathrm{~cm}$ (inner diameter) at a flow of 1 SLPM (Table 2). In the sample block (SB), absorption of $\mathrm{NH}_{3}$ from the air flow takes place via a gas-permeable PTFE (polytetrafluoroethylene) membrane into an acid buffer (or "stripping") solution, with a scrubbing efficiency of close to $100 \%$. Ammonium-containing aerosols are not retained by the sampling membrane. This was verified by laboratory experiments where less than $1 \%$ and $3 \%$ of $\left(\mathrm{NH}_{4}\right)_{2} \mathrm{SO}_{4}$ and $\mathrm{NH}_{4} \mathrm{NO}_{3}$ particles, respectively, were captured (Otjes et al., 1999). The $\mathrm{pH}$ of the stripping solution is subsequently raised by addition of sodium hydroxide, which triggers the release and transfer of the captured $\mathrm{NH}_{3}$ through a second PTFE membrane in the detector block (DB), into a stream of pure deionized water in counter-flow on the other side of the membrane. The $\mathrm{NH}_{3}$ transfer efficiency of the AMFIA detector block is $90 \%$. The $\mathrm{NH}_{4}^{+}$concentration in the solution is determined by a conductivity measurement, and calibration is made using aqueous $\mathrm{NH}_{4}^{+}$standard solutions (cf. Slanina et al., 2001). As with similar instruments based
Table 1. Characteristics of the $\mathrm{NH}_{3}$ instruments compared in this study.

\begin{tabular}{|c|c|c|c|}
\hline & Institute & $\begin{array}{l}\text { Detection } \\
\text { limit }(2 \sigma)\end{array}$ & $\begin{array}{c}\text { Sampling } \\
\text { time }\end{array}$ \\
\hline AiRRmonia & ART, Zürich, Switzerland & $120 \mathrm{pptv}$ & $15 \mathrm{~min}$ \\
\hline GRAEGOR & MPIC, Mainz, Germany & 94 pptv & $30 \mathrm{~min}$ \\
\hline PTR-MS & University of Innsbruck, Austria & $90-270$ pptv $^{(1)}$ & $1 \min ^{(2)}$ \\
\hline
\end{tabular}

(1) The background and hence the detection limit for the PTR-MS varies with absolute humidity, see text. ${ }^{(2)}$ The sampling time for the PTR-MS is variable (seconds to minutes), but in this paper we only present 1-min sampling time data.

Table 2. Description of the different inlets for the $\mathrm{NH}_{3}$ instruments in this study.

\begin{tabular}{|c|c|c|c|}
\hline & AiRRmonia & GRAEGOR & PTR-MS \\
\hline Type & $\mathrm{PE}$ & PFA & PFA \\
\hline Length & $5 \mathrm{~cm}$ & $30 \mathrm{~cm}$ & $17 \mathrm{~m}$ \\
\hline Inner diameter, $\mathrm{cm}$ & 0.17 & 0.8 & 0.95 \\
\hline Flow, SLPM & 1 & 16.7 & 15 \\
\hline Air speed, $\mathrm{ms}^{-1}$ & 7.3 & 5.5 & 3.5 \\
\hline Reynolds number & 860 & 3880 & 2470 \\
\hline Surface to volume ratio, $\mathrm{m}^{-1}$ & 2350 & 500 & 420 \\
\hline Residence time, $\mathrm{s}$ & 0.007 & 0.054 & 4.8 \\
\hline
\end{tabular}

on quantitative sampling of gaseous compounds into liquids and subsequent analysis in the liquid phase, the establishment of constant and precise liquid flows for all solutions is critical. The AiRRmonia applies syringe pumps for this purpose; their performance was verified by equipping the instrument with a liquid flow meter (Liquiflow L1, Bronkhorst $\mathrm{NL}$ ) and continuously monitoring the total liquid flow.

The response time of the analyzer is of the order of 10$15 \mathrm{~min}$ and depends on the liquid flow rate, and thus on syringe pump speed. Detection limit and accuracy of the AiRRmonia have previously been determined as $0.1 \mu \mathrm{g} / \mathrm{m}^{3}$ and 3\%, respectively (Erismann et al., 2001). For an estimate representative of the measurement period presented here, we used the $2 \sigma$ (twice the observed standard deviation) from conductivity measurements in the field without air flow in sampling block as an estimate for the detection limit and twice the observed standard deviation from calibrations in the field as an estimate for the accuracy. The resulting values were $0.08 \mu \mathrm{g} / \mathrm{m}^{3}$ or $120 \mathrm{pptv}$ for detection limit and $10 \%$ accuracy at $\mathrm{NH}_{3}$ mixing ratios of 5 ppbv, c.f. Table 1. The detector block was placed $1.25 \mathrm{~m}$ above the grass field. The AiRRmonia was operated by personnel from Agroscope Reckenholz-Tänikon Research Station (ART) in Zürich, Switzerland. 


\subsubsection{GRAEGOR}

The recently developed GRadient of AErosol and Gases Online Registrator (GRAEGOR) measures mixing ratios of water-soluble gases, such as $\mathrm{NH}_{3}, \mathrm{HNO}_{2}, \mathrm{HNO}_{3}, \mathrm{HCl}$, $\mathrm{SO}_{2}$ and their related aerosol compounds $\mathrm{NH}_{4}^{+}, \mathrm{NO}_{3}^{-}$, $\mathrm{Cl}^{-}, \mathrm{SO}_{4}^{2-}$ (Thomas et al., 2009). The instrument consists of two sampling units, an analytical part, and a vacuum pump (Becker VT 4.16). The sampled air is drawn through two PFA (perflouroalkoxy) Teflon tubing connections $\left(\mathrm{d}_{i}=0.8 \mathrm{~cm}, \mathrm{l}=30 \mathrm{~cm}\right.$, Table 2$)$ to two sampling units that can be placed at two different heights to measure gradients. Water-soluble gases and aerosol species are collected simultaneously by two horizontally aligned rotating wet-annular denuders (WAD or WRD) and two Steam-Jet Aerosol Collectors (SJAC), respectively (Slanina et al., 2001; Trebs et al., 2004). A critical orifice provides controlled sample airflows of approx. $16.71 \mathrm{~min}^{-1}(293.15 \mathrm{~K}$ and $1013.25 \mathrm{hPa}$ ) through each of the WRD/SJAC sampling lines. The airflow was regularly checked with a Gilibrator Air Flow Calibration System. To minimize wall losses of sticky gases such as $\mathrm{HNO}_{3}$ (Neuman et al., 1999), no preimpactor or cyclone was connected in front of the inlet. In contrast to previous studies that have employed similar instrumentation (e.g., Trebs et al., 2004), one major improvement of the GRAEGOR is the application of syringe pumps for the precise transport of liquids which is crucial for accurate analyses (cf. section above). The sample flow through the system is constant at $0.333 \mathrm{ml} \mathrm{min}^{-1}$ and is controlled with a Bronkhorst liquid flow meter. The sample solutions are analyzed on-line using ion chromatography (IC) for anions (results are not included in this study). Ammonium $\left(\mathrm{NH}_{4}^{+}\right)$is analyzed using the same method as applied in the AiRRmonia (ammonium flow injection analysis, AMFIA). However, the AMFIA detector in GRAEGOR only has a $\mathrm{NH}_{3}$ transfer efficiency of $30 \%$ (Slanina et al., 2001). The detector was calibrated in the same way as that of the AiRRmonia using standard solutions of $\mathrm{NH}_{4}^{+}$. The accuracy is $12 \%$ as determined by Gaussian error propagation, including uncertainties of the sampled air volume, the liquid flow and conductivity detection. The detection limit for $\mathrm{NH}_{3}$ was estimated from field blanks ( $2 \sigma$-definition) to 94 pptv (Table 1). The air samples that the GRAEGOR analyzes represent an average of the second half of each hour. This is the fastest sampling time achievable when GRAEGOR is operated as gradient monitor since two gas samples and two aerosol samples need to be analyzed subsequently and each analytical cycle takes $15 \mathrm{~min}$. The response time of GRAEGOR, i.e. the time it takes for the signal to drop to $1 / \mathrm{e}$ of the starting value (ambient $\mathrm{NH}_{3}$ mixing ratio) after switching off the air pump, was shown to be $58 \pm 2 \mathrm{~min}$ (cf. Thomas et al., 2009). For gradient measurements, the lower measurement height was $0.37 \mathrm{~m}$ and the upper measurement height was $1.23 \mathrm{~m}$. In this paper we only present data from the upper level measurements. The GRAEGOR was oper- ated by personnel from Max Planck Institute for Chemistry (MPIC) in Mainz, Germany.

\subsubsection{PTR-MS}

Proton Transfer Reaction Mass Spectrometry (PTR-MS) is a state-of-the-art chemical ionization mass spectrometry (CIMS) technique for highly sensitive on-line measurements of volatile organic compounds (VOC) as described in Hansel et al. (1995) and Lindinger et al. (1998). A new technique for fast measurements of gas phase $\mathrm{NH}_{3}$ using the PTRMS instrument has recently been presented by Norman et al. (2007). Oxygen $\left(\mathrm{O}_{2}\right)$ is used as a source gas to produce $\mathrm{O}_{2}^{+}$as chemical ionization $(\mathrm{CI})$ reagent instead of $\mathrm{H}_{3} \mathrm{O}^{+}$. The $\mathrm{O}_{2}^{+}$ions react with the $\mathrm{NH}_{3}$ molecules via the electron transfer reaction $\mathrm{O}_{2}^{+}+\mathrm{NH}_{3} \rightarrow \mathrm{NH}_{3}^{+}+\mathrm{O}_{2}$ which occurs at collision rate. Primary $\left(\mathrm{O}_{2}^{+}\right)$and product ions $\left(\mathrm{NH}_{3}^{+}\right)$are separated by a quadrupole mass spectrometer and detected using an electron multiplier SEM pulse counting system. The correct terminology of the instrument would be ETR-MS (Electron Transfer Reaction Mass Spectrometer), since it uses electron transfer instead of proton transfer as in the conventional PTR-MS. However the instrument itself is not changed and we will through the paper use the well-established terminology PTR-MS when referring to the instrument. A detailed description of the instrument settings, sensitivity and selectivity can be found in Norman et al. (2007). During laboratory tests the detection limit $(2 \sigma)$ was found to be $90 \mathrm{pptv}$ for a $1 \mathrm{~s}$ signal integration time at dry conditions, increasing to 270 pptv for humid conditions (Table 1). The instrumental time response, defined by $1 / \mathrm{e}^{2}$ decay in the calibration signal was around $30 \mathrm{~s}$. The instrument used for these measurements was a conventional PTR-MS instrument built at the University of Innsbruck. The PTR-MS inlet consisted of a $17 \mathrm{~m}$ long $\mathrm{d}_{i}=0.95 \mathrm{~cm}$ PFA tubing with a flow of 15 SLPM (Table 2). The inlet was not heated, but covered with aluminum foil to minimize effects from direct solar radiation on the tube. The inlet was mounted $1.25 \mathrm{~m}$ above the grass field on a tripod in close vicinity to the other two instruments on the intensively managed plot. The sample inlet to the PTRMS drift tube consisted of a $15 \mathrm{~cm}$ silica coated stainless steel tube (Sulfinert ${ }^{\circledR}$, Restek Corp., Bellefonte, PA, USA) which was pressure and temperature controlled. The passivated stainless steel tube sampled air from the centre of the main inlet tubing. The air flow into the PTR-MS instrument was $\sim 30 \mathrm{sccm}$. The sampling time for the PTR-MS instrument used in this study varied between $0.5 \mathrm{~s}$ to $30 \mathrm{~s}$, but we only present $1 \mathrm{~min}$ averages (Table 1 ).

The PTR-MS instrument was calibrated using a permeation device manufactured by Real Sensors Inc. (Hayward, California, USA). Given the high uncertainty in the specified permeation rate, the permeation rate was re-calibrated using denuders coated with 5\% citric acid solution as in Sutton et al. (2001). The estimated accuracy using this calibration approach is $\pm 10 \%$. The permeation tube was kept 

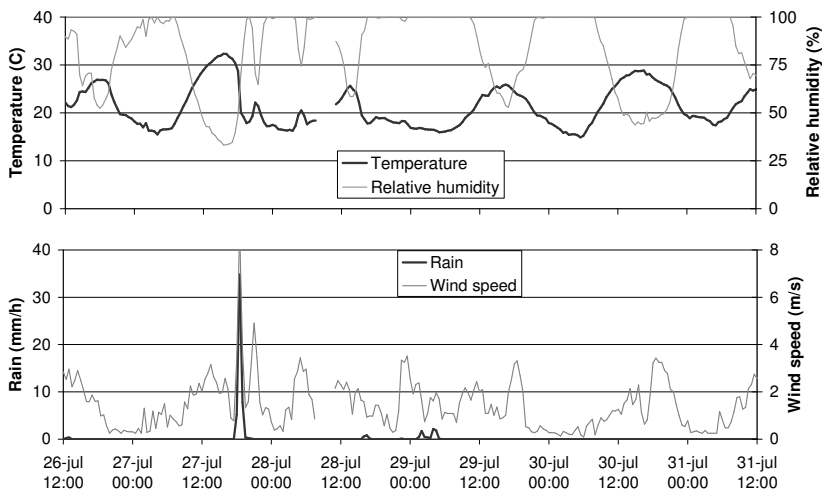

Fig. 1. Observed meteorological parameters for the 5-day intercomparison period.

in a temperature controlled oven at $30^{\circ} \mathrm{C}$ and was continuously flushed with $\mathrm{NH}_{3}$ free air. $\mathrm{NH}_{3}$ free air was generated using a platinum and palladium $(\mathrm{Pt} / \mathrm{Pd})$ catalyst operated at $350^{\circ} \mathrm{C}$ (Parker-Balston, Haverhill, MA, USA). $\mathrm{NH}_{3}$ free air was also generated using oxalic acid coated filters. Using one or two stage dilution with $\mathrm{NH}_{3}$ free air from the $\mathrm{Pt} / \mathrm{Pd}$ catalyst and/or the oxalic acid $\mathrm{NH}_{3}$ scrubber, the instrument was calibrated in the field for mixing ratios between 8 and 150 ppbv. Details about the calibration system can be found in Norman et al. (2007). The PTR-MS was operated by personnel from the Institute for Ion and Applied Physics at the University of Innsbruck, Austria.

\section{Results}

\subsection{Time series analysis}

The field site was equipped with a meteorological station providing half-hour averages of air temperature, relative humidity, precipitation, wind speed and wind direction. The meteorological conditions during the measurement period are presented in Fig. 1. The period was dominated by relatively high daytime temperatures between $20^{\circ}$ and $30^{\circ} \mathrm{C}$. There was a heavy thunderstorm on the 27 th July with almost $40 \mathrm{~mm} / \mathrm{h}$ rain and heavy winds and a sharp drop in temperature. A longer rain period occurred in the morning of the 29 th with mostly light rain. The relative humidity was close to $100 \%$ during nighttime and mostly dropped to below $50 \%$ during daytime. Figure 2 shows the time-series of measured $\mathrm{NH}_{3}$ mixing ratios during the intercomparison period for all three instruments. The thunderstorm in the evening of 27 th July caused a power failure and the measurements started again in the morning of 28th July. The time series analysis shows an overall good agreement between the three different instruments. The time course of $\mathrm{NH}_{3}$ shows large variations, with mixing ratios around $10-15$ ppbv on 26th July and in the morning of 27 th July. $\mathrm{NH}_{3}$ levels dropped in the morning of 27 th July and continued falling until the power fail-

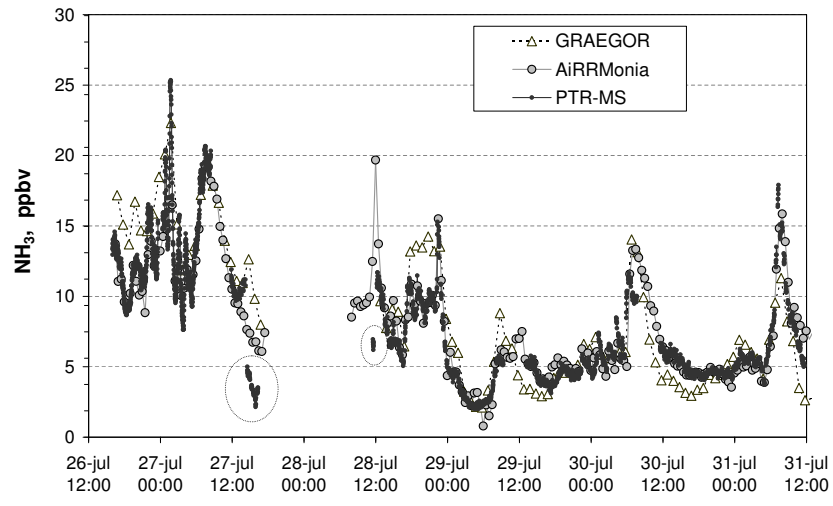

Fig. 2. $\mathrm{NH}_{3}$ mixing ratios measured $1.25 \mathrm{~m}$ above the intensively managed grass field. The data are presented in $1 \mathrm{~min}, 30 \mathrm{~min}$ and $1 \mathrm{~h}$ sampling time for the PTR-MS, AiRRmonia and GRAEGOR, respectively. PTR-MS data within the circles are discussed separately.

ure in the evening. The mixing ratios were lower following the heavy thunderstorm rainfall. The PTR-MS data showed a sudden drop in mixing ratio during the rainfall as well as during the start up in the morning after (data within the circles in Fig. 2). As discussed later in the paper, this drop was most likely caused by water condensation in the main inlet line. On 28th July highly variable mixing ratios were observed with a sharp drop in the late evening before the onset of rainfall. The period from 29th to 31st July was characterized by a sharp $\mathrm{NH}_{3}$ peak every morning around 09:00 a.m. Similar increases during morning hours have been observed over grassland sites elsewhere, e.g., by Trebs et al. (2005). The mixing ratio typically decreased throughout the afternoon.

The different sampling times of the three instruments result in slightly different features of the temporal $\mathrm{NH}_{3}$ structure. The 1-min PTR-MS data indicate fast $\mathrm{NH}_{3}$ variations on 26th July and early morning of 27th July. A detailed version of the $\mathrm{NH}_{3}$ levels observed by the PTR-MS and the AiRRmonia instruments during this period is shown in Fig. 3. While both instruments found a very similar mixing ratio pattern at half-hour sampling time, the PTR-MS was able to capture additional changes of $\mathrm{NH}_{3}$ occurring at the time scale of minutes. These fast variations may be caused by small scale changes in the advection of air masses close to the ground, as supported by the concurrent variation of the wind speed.

The absolute levels agree reasonably well between the instruments on average throughout the period, with some periods with significant differences. The AiRRmonia measured lower mixing ratios than the other two instruments before the thunderstorm on 27th July, but most of the time, the PTRMS and the AiRRmonia followed each other overall rather closely, while the GRAEGOR occasionally showed some divergence from the other two instruments. The GRAEGOR mixing ratios were $20-30 \%$ higher than both the PTR-MS 


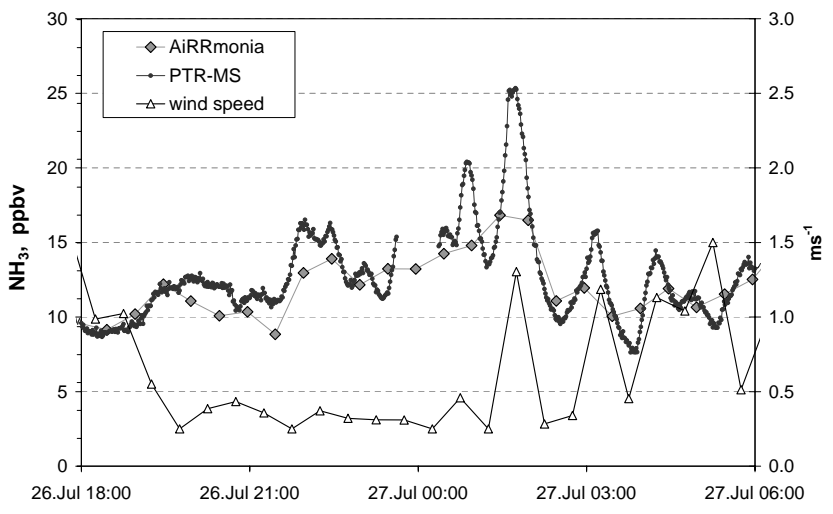

Fig. 3. The AiRRmonia and the PTR-MS data for a $12 \mathrm{~h}$ period on the 26th and 27th July when fast $\mathrm{NH}_{3}$ variations were observed.

and the AiRRmonia levels in the afternoon of 26th July and in the afternoon of 28th July following rain events with associated high relative humidities (Fig. 1), but they were 20$40 \%$ lower in the early mornings of 29th and 30th July as well as during midday on 29th, 30th and 31st July.

\subsection{Regression analyses}

Hourly averaged values were calculated from the data presented in Fig. 2 (the PTR-MS data in the circles excluded). Bivariate regression analyses of the calculated hourly averages are presented in Fig. 4. As for the time series analysis an overall good agreement was found between all three instruments. The correlation between the PTR-MS and the AiRRmonia (Fig. 4a) was found to be excellent $\left(r^{2}=0.94\right)$. The AiRRmonia shows marginally lower mixing ratios than the PTR-MS, reflected in a slope of 0.97 . A brief laboratory intercomparison between the AiRRmonia analyzer and the PTR-MS instrument presented in Norman et al. (2007) also showed an $r^{2}>0.95$ and difference of mixing ratios $<5 \%$. The regression also shows that the AiRRmonia and the PTRMS depict a linear correlation throughout the whole measured mixing ratio range with an offset of less than $0.25 \mathrm{ppbv}$.

The comparison between the GRAEGOR and the AiRRmonia (Fig. 4b) shows the poorest correlation with an $r^{2}=0.79$. The GRAEGOR showed on average higher mixing ratios than the AiRRmonia at mixing ratios above $10 \mathrm{ppbv}$ but also slightly lower at mixing ratios below 5 ppbv. This resulted in a slope of 0.78 and an offset of 1.25 ppbv.

The comparison between the GRAEGOR and the PTRMS (Fig. 4d) resulted in a correlation coefficient $r^{2}=0.85$. As for the comparison with the AiRRmonia, the GRAEGOR showed higher mixing ratios above $10 \mathrm{ppbv}$ and slightly lower mixing ratios below 5 ppbv. This resulted in a slope of 0.80 and an offset of $0.96 \mathrm{ppbv}$.

The GRAEGOR data shown in Fig. $4 \mathrm{~b}$ and d were derived using a calibration made on the 26th of July before the power failure when (liquid) temperatures were $>30^{\circ} \mathrm{C}$. In contrast,
Fig. $4 c$ and e show regressions of the GRAEGOR data with AiRRmonia and PTR-MS, respectively using a calibration made on 1st of August (at the end of the intercomparison period) when (liquid) temperatures were $<28^{\circ} \mathrm{C}$. While $r^{2}$ does not change much using the latter calibration made at lower temperatures, the other regression parameters improve substantially (slopes of 0.92 and 0.95 and offsets of 0.58 and $0.27 \mathrm{ppbv}$, respectively).

\section{Discussion}

The difficulty of measuring atmospheric $\mathrm{NH}_{3}$ is demonstrated in the wide variety of results from $\mathrm{NH}_{3}$ intercomparison exercises found in literature.

The study by Wiebe et al. (1990) showed that the measurements including filter packs and annular denuders agreed to within $\pm 30 \%$ for $\mathrm{NH}_{3}$ levels higher than $1.5 \mathrm{ppbv}$, but with a relatively coarse sampling time (minimum $4 \mathrm{~h}$ ). The five different $\mathrm{NH}_{3}$ measurement techniques tested by Williams et al. (1992) all agreed within a factor of two for $\mathrm{NH}_{3}$ levels above 0.5 ppbv. The photofragment instrument (PF/LIF) and the citric acid coated denuders (CAD/IC) however agreed within $15 \%$ for all measured ambient mixing ratios $(0.2-$ $5 \mathrm{ppbv}$ ) for a sampling time of $2-8 \mathrm{~h}$.

The detailed study by Mennen et al. (1996) showed that the wet-annular rotating denuder (WRD) met all the requirements for air quality monitoring on one hour sampling. The study also showed that both the DOAS and the $\mathrm{NO}_{\mathrm{x}}$ converter instruments showed correlations of $r^{2}>0.9$ with the WRD, but were found not to be accurate enough for low concentrations. The photoacoustic monitor was rejected because it could not be operated without frequent attention and the thermodenuders were rejected due to their low sampling time.

The field intercomparison by Milford et al. (2000) showed that the AMANDA and the DS-FIA had an overall difference of $35 \%$ for 30 min sampling times, but also with a substantial scatter of the data. The intercomparison reported by Fehsenfeld et al. (2002) showed that the CIMS and the $\mathrm{MoO}_{\mathrm{x}}$ converter method correlated with the citric acid denuder with an $r^{2}>0.91$ for sampling times of at least $2 \mathrm{~h}$. However, the averaged concentration ratio for the CIMS and the $\mathrm{MoO}_{\mathrm{x}}$ converter difference method compared to the denuder was 0.8 and 1.75 , respectively.

The two different CIMS instruments, tested in the field by Nowak et al. (2006) with ambient levels ranging 0.4 to 13 ppbv showed a difference of $17 \%$ and an $r^{2}=0.71$ for a sampling time of one minute. The $r^{2}$ would be higher if averages over longer periods were calculated.

Among the six different techniques tested in the laboratory by Schwab et al. (2007), all except the modified chemiluminescence analyzer were able to measure mixing ratios within $25 \%$ of the expected values under stable conditions between 0 and 20 ppbv. However the TDLAS and the LOPAP showed on average the best agreement with the expected values. The 


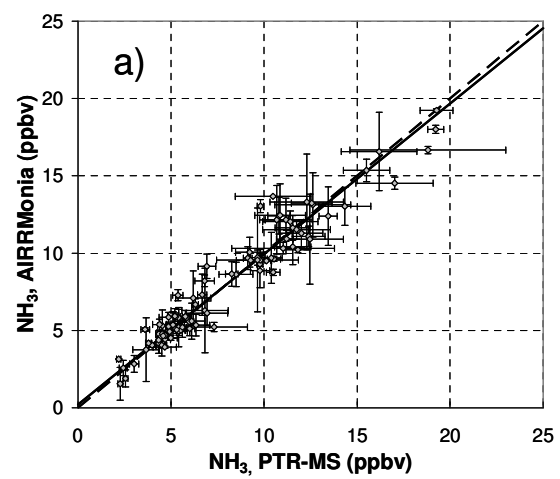

\begin{tabular}{|l|c|c|c|c|}
\hline & \multicolumn{2}{|c|}{} & \multicolumn{2}{c|}{$\mathbf{y}=\mathbf{A x}+\mathbf{B}$} \\
\hline Figure & $\mathbf{N}$ & $\mathbf{r}^{2}$ & $\mathbf{A}$ & $\mathbf{B}$ \\
\hline a) & 93 & 0.94 & $0.97 \pm 0.03$ & $0.22 \pm 0.23$ \\
\hline b) & 97 & 0.79 & $0.78 \pm 0.04$ & $1.25 \pm 0.36$ \\
\hline c) & 97 & 0.79 & $0.92 \pm 0.04$ & $0.58 \pm 0.40$ \\
\hline d) & 86 & 0.85 & $0.80 \pm 0.03$ & $0.96 \pm 0.33$ \\
\hline e) & 86 & 0.83 & $0.95 \pm 0.04$ & $0.27 \pm 0.38$ \\
\hline
\end{tabular}
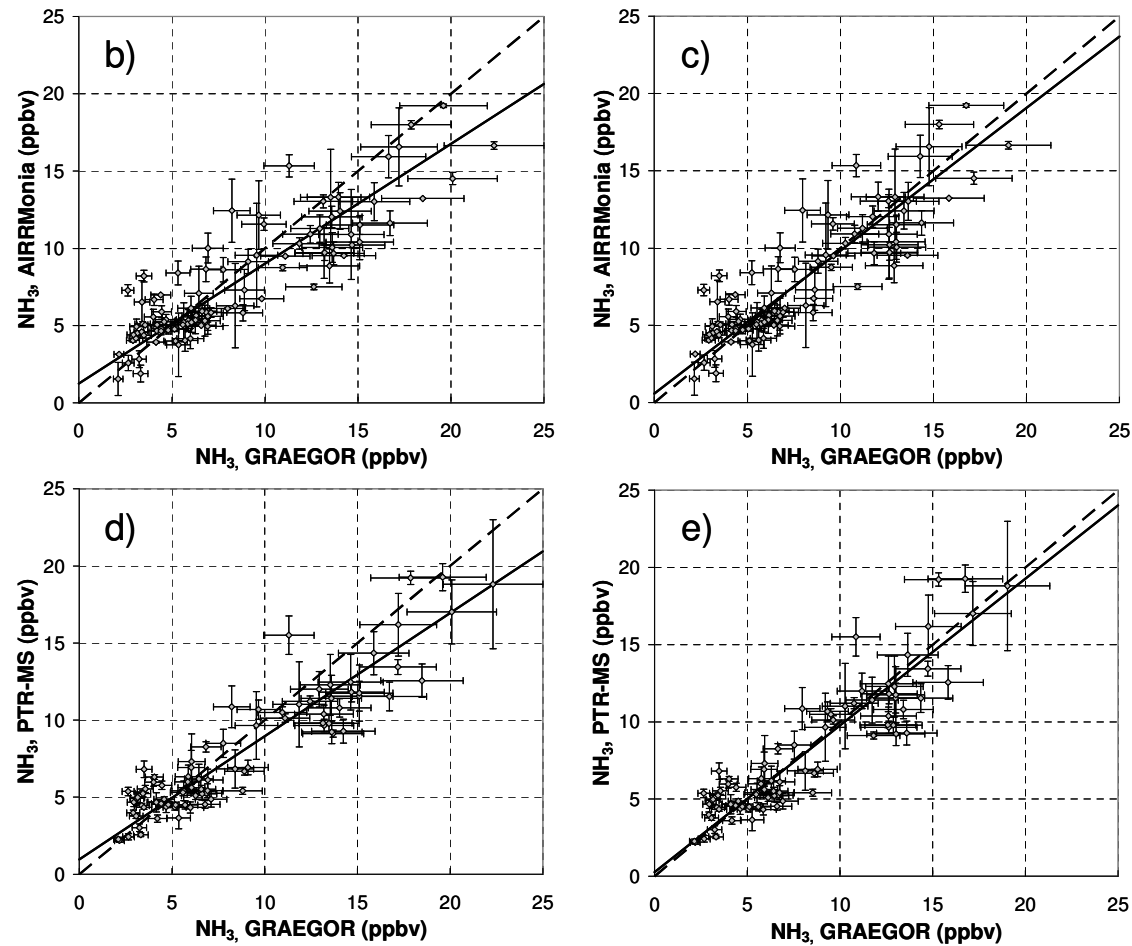

Fig. 4. Bivariate regression plots of hourly averaged data from all three instruments. Data in (a), (c) and (e) represent hourly averaged data from Fig. 2. (c) and (e) are the same as (b) and (d) respectively, but with a different calibration for the GRAEGOR (see text). The error bars represent the observed variability ( $\pm \sigma$, standard deviation) within the respective hour (the GRAEGOR only produces one value every hour and in this case error bars present the instrument accuracy of $\pm 12 \%$ ). The dashed line gives the 1:1 relationship and the solid line gives the result of a reduced major axis regression. $\mathrm{N}$ is the number of data points.

TDLAS was also found to have shortest time response during spiking tests.

The intercomparison of a QCLAS, a TDLAS and an AMANDA system by Whitehead et al. (2008) found correlations $\left(r^{2}\right)$ to be good, ranging between 0.74 and 0.98 for concentration measurements during and after slurry application, with better correlations during the high concentration period. Despite the high correlations, the averaged concentration ratio between individual systems varied significantly (between 0.44 and 1.3).

The three instruments tested in this study showed a good correlation with $r^{2}>0.79$ for $1 \mathrm{~h}$ averaged values. Uncorrected mixing ratios levels agreed to within $22 \%$ with offsets ranging from 0.22 to $1.25 \mathrm{ppbv}$. The PTR-MS and the AiRRmonia agreed to $3 \%$ with an $r^{2}=0.94$. The results in this study are well in line with the intercomparison studies mentioned above and the agreement between these very different measurement concepts is encouraging.

There exist several possibilities for the deviations from a 1:1 correlation. The departures from the 1:1 ratio shown in Fig. 4a to e were not found to be correlated to one particular meteorological parameter (e.g., wind speed and temperature). Most likely the observed differences were largely attributable to a combination of different effects, which are discussed below. 


\subsection{Calibration procedures and temperature influence}

The PTR-MS method is not reported to be temperature dependent (Norman et al., 2007). Furthermore, the instrument was placed inside a temperature-controlled trailer. The GRAEGOR and the AiRRmonia instruments were placed outside and were therefore exposed to temperature fluctuations at the field site. The AiRRmonia and the GRAEGOR use identical analytical procedures (AMFIA, see above) and were calibrated with liquid standards, while the PTR-MS was calibrated with a gaseous standard. Any dependence of the scrubbing- or collection efficiency on the mixing ratios for the GRAEGOR and the AiRRmonia could therefore lead to differences over the observed mixing ratio range. The PTRMS has a linear response to the gaseous $\mathrm{NH}_{3}$ standard (Norman et al., 2007). In contrast, the conductivity measurements in the AiRRmonia and the GRAEGOR feature a quadratic response to the introduced liquid standards. Moreover, the transfer of $\mathrm{NH}_{3}$ through the semi-permeable PTFE membrane in the detector block and the conductivity response are a function of temperature (Decuq et al., 2008), which is corrected for using an empirically derived relationship (see e.g., Trebs et al., 2004).

In case of the GRAEGOR, substantial differences between calibrations made at different temperatures were observed (as mentioned above). While the AiRRmonia detector was calibrated in the early morning when temperatures were around $15-20^{\circ} \mathrm{C}$ (Fig. 1) the first GRAEGOR calibration was performed on 26th of July when (liquid) temperatures $>30^{\circ} \mathrm{C}$ were measured. The calibration on 1st of August (at the end of the intercomparison period) was made at (liquid) temperatures $<28^{\circ} \mathrm{C}$ (cf. Fig. $4 \mathrm{~b}$ and d) and results in $\mathrm{NH}_{3}$ values that were on average about $15-20 \%$ lower than the mixing ratios based on the calibration on the 26th of July. Hence, the slope and offset of the regression between GRAEGOR and the other instruments improves using the calibration from 1st of August as observed in Fig. 4c and e (cf. Sect. 3.2). The following GRAEGOR calibrations at the field site with liquid temperatures around $25^{\circ} \mathrm{C}$ agreed within $5 \%$ with that on the 1st of August, suggesting that it is critical to perform calibrations at temperatures higher than $30^{\circ} \mathrm{C}$. It is important to note, that the lower $\mathrm{NH}_{3}$ transfer efficiency of the AMFIA in GRAEGOR (30\% compared to $90 \%$ of the AiRRmonia) would generally promote the temperature effects. Decuq et al. (2008) propose that the empirically derived relationship for the AMFIA detector does not give accurate results (particularly for high temperatures) and a more suitable correction for temperature effects may be required.

Figure 5 shows a combined graph of the time series for both calibrations of the GRAEGOR data. The difference between the two calibrations was larger before the power failure on the 27 th of July. The power failure caused a loss of the AMFIA deionized water background conductivity signal, which mainly serves to monitor the water quality and is used in the calculation of the $\mathrm{NH}_{3}$ mixing ratio. The calibration

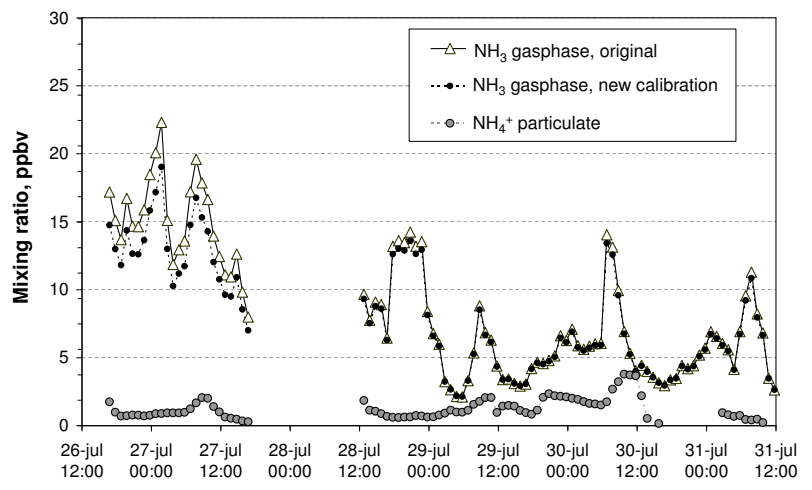

Fig. 5. Gas phase $\mathrm{NH}_{3}$ mixing ratios and particulate $\mathrm{NH}_{4}^{+}$mixing ratios measured $1.25 \mathrm{~m}$ above the grass field from the GRAEGOR instrument. The $\mathrm{NH}_{3}$ data is presented for two different calibrations of the GRAEGOR (see text).

made on 1st of August includes this signal loss (i.e., the AMFIA signal is derived only from the sample conductivity). Thus the data before the power failure, which still contained the background conductivity, are probably overcorrected using the calibration from the 1st of August.

\subsection{Particle interference}

One major complication for $\mathrm{NH}_{3}$ sampling described e.g., by Parrish and Fehsenfeld (2000) is the simultaneous presence of $\mathrm{NH}_{\mathrm{x}}$ in the gaseous, particulate and liquid phases. For accurate sampling of gaseous $\mathrm{NH}_{3}$ the particulate and gas phase should be separated before sampling in order to avoid positive artifacts by sampling of particles. The GRAEGOR separates the gas phase from the particulate phase and its measured $\mathrm{NH}_{3}$ mixing ratios are therefore not expected to be affected by particles. The AiRRmonia samples through a gas-permeable membrane with particle interference below 3\% (Otjes and Erisman, 1999). The PTR-MS has no separation of gas and particulate phase in front of the inlet and it has not yet been tested for any particle interference. Thus, it is not known what happens to particulate $\mathrm{NH}_{4}^{+}$in the low pressure system of the instrument. However, large inlet cross sectional area in combination with high flow rates largely reduces the interference of larger particles. The aerosol $\mathrm{NH}_{4}^{+}$ measured with the GRAEGOR during the intercomparison period ranged from 0.3 to $3.8 \mathrm{ppbv}$ (Fig. 5), which was between 5 and $70 \%$ of the $\mathrm{NH}_{3}$ mixing ratio. We expect that particle interferences only had a minor contribution to the observed $\mathrm{NH}_{3}$ differences. Potentially this might have been the case when GRAEGOR measured lower $\mathrm{NH}_{3}$ mixing ratios than the AiRRmonia and the PTR-MS during midday on the 29th, 30th of July when aerosol $\mathrm{NH}_{4}^{+}$was on average $50 \%$ of the measured $\mathrm{NH}_{3}$ mixing ratio. During these periods the sharp drop of relative humidity potentially promoted evaporation of $\mathrm{NH}_{3}$ from aerosol and ground surfaces, a dynamic feature that was most likely not captured to the same extent by all instruments. 


\subsection{Inlets and humidity dependence}

Several studies have reported difficulties measuring $\mathrm{NH}_{3}$ due to its interaction with the surface material of the inlets (e.g., Whitehead et al., 2008; Yokelson et al., 2003; Parrish and Fehsenfeld, 2000). Teflon (PFA and PFTE) and Polyethylene (PE) have been found to be well suited materials (Yokelson et al., 2003; Shah et al., 2006; Whitehead et al., 2008), but it is still recommended to choose the inlet length as short as possible to avoid losses (Fehsenfeld et al., 2002). The instruments in this study used a wide variety of inlet lengths and flow regimes as presented in Table 2. The PTR-MS used a $17 \mathrm{~m}$ long PFA with $\mathrm{d}_{i}=0.95 \mathrm{~cm}$, the inlet of the GRAEGOR consisted of $30 \mathrm{~cm}$ long PFA tubing with $\mathrm{d}_{i}=0.8 \mathrm{~cm}$ and the AiRRmonia inlet was made of PE and had a length of only $5 \mathrm{~cm}$ and $\mathrm{d}_{i}=0.17 \mathrm{~cm}$.

We observed losses in the PTR-MS inlet during and directly after the thunderstorm on the 27th July. During the rainfall the inlet tubing was cooled by water on the outside of the inlet apparently causing condensation in the inlet and uptake of $\mathrm{NH}_{3}$ on the tubing walls. This was clearly seen in the data with a sudden drop of more than $50 \%$ of the mixing ratios in comparison to the other instruments (data shown within the circles in Fig. 2). No loss of $\mathrm{NH}_{3}$ in the PTR-MS inlet compared to the other instruments was observed during the other periods without rainfall although the relative humidity was close to $100 \%$ during several nights. The AiRRmonia has similar if not less potential than GRAEGOR for adsorption of $\mathrm{NH}_{3}$ on inlet walls. Most likely, adsorptiondesorption in the AiRRmonia and the PTR-MS were not important, since largest differences occurred between GRAEGOR and PTR-MS/AiRRmonia. These results suggest that no losses of $\mathrm{NH}_{3}$ on the PFA tubing surface to the PTR-MS instrument were observed when compared to the AiRRmonia and the GRAEGOR inlet as long as the tubing was not cooled causing condensation. An optimal design of an inlet might therefore be thermal insulation and if possible heating to a few degrees above the ambient temperature, keeping in mind that large temperature differences between outside and the inlet air cause aerosol ammonium nitrate to evaporate forming artifact $\mathrm{NH}_{3}$.

The PTR-MS has a background signal that is observed to increase from 70 to 400 pptv with increasing humidity associated with also an increase in detection limit (cf. Table 1; Norman et al., 2007). A correction for the observed absolute humidity was therefore applied to the data. The departures from the 1:1 ratio observed in Fig. 4 for any of the correlations were not found to be correlated to the prevailing humidity.

\section{Summary and conclusions}

This paper compares measurements of atmospheric $\mathrm{NH}_{3}$ by three different instruments performed at the Oensingen in- tensively managed grassland site during 5 days in July and August 2006 within the framework of NitroEurope.

During the intercomparison period ambient temperatures were relatively high $\left(18-32^{\circ} \mathrm{C}\right)$ and relative humidities ranged from 30 to $100 \%$.

The instruments included in the experiment were the AiRRmonia, the GRAEGOR, and a modified PTR-MS instrument. The GRAEGOR collects air samples using wetannular denuders combined with steam-jet aerosol collectors, analysis is performed on-line using ammonium flow injection. The AiRRmonia analyzer samples air through a gas-permeable membrane and analysis is performed in the same way as with the GRAEGOR. The modified PTR-MS approach is based on chemical ionization mass spectrometry using $\mathrm{O}_{2}^{+}$primary reagent ions.

All three instruments measured simultaneously at the site for a period of 5 days. During the intercomparison period the gas phase $\mathrm{NH}_{3}$ mixing ratios varied between 2 and 25 ppbv. Correlation analyses between the instruments for 1-h averages showed correlation coefficients $r^{2}>0.79$ with the highest grade of correlation between the AiRRmonia and the PTR-MS $\left(r^{2}=0.94\right)$. According to the regression analysis the GRAEGOR measured on average about $20 \%$ higher mixing ratios than both the AiRRmonia and the PTR-MS instruments. One potential cause for this deviation was unusually high temperatures during the period the GRAEGOR was calibrated in the 5-day intercomparison phase. An analysis of all calibrations performed during the multi-week deployment of the GRAEGOR revealed that this particular calibration stood out with a significantly different sensitivity curve, whereas the all other calibration agreed within 5\%. Using these other GRAEGOR calibrations for data analysis, the average difference decreased to $<7 \%$ and the offset was $<0.6 \mathrm{ppbv}$. If obvious condensation events in the PTR-MS sampling line were excluded, AiRRmonia and PTR-MS measurements agreed to within $3 \%$ with an offset $<0.25$ ppbv.

During conditions favoring condensation in inlet lines, the PTR-MS measured significantly less $\mathrm{NH}_{3}$ than the wet chemical systems, which had much shorter inlets. This underlines the importance of a careful inlet design and needs to be considered for any instrument measuring $\mathrm{NH}_{3}$ directly in the gas phase.

The three instruments included in this study have different fields of application. The AiRRmonia is developed for time-extended $\mathrm{NH}_{3}$ monitoring in the field without intensive maintenance in contrast to both the GRAEGOR and the PTRMS. The GRAEGOR instrument allows to selectively and simultaneously measure several gas and particulate components and to sample simultaneously at two different levels for aerodynamic gradient studies. The PTR-MS measures $\mathrm{NH}_{3}$ at a sampling time of seconds, although the effective response time is somewhat slower probably because of adsorption effects within the instrument (Norman et al., 2007). Still, it is considerably faster than the other instruments which have a sampling time of $30 \mathrm{~min}$ to one hour. The PTR-MS 
is therefore suitable for process based studies or for measurements on moving platforms where fast changes of mixing ratios occur, provided that inlet lines cause no significant damping of rapidly changing mixing ratio signals.

The results from these measurements are well in line with previously reported intercomparisons proving that these three instruments are suitable for atmospheric $\mathrm{NH}_{3}$ measurements under the tested conditions.

Acknowledgements. The EU project NitroEurope (Contract 017841) is funded under the EC 6th Framework Programme for Research and Technological Development. MN was funded by FORMAS, The Swedish Research Council for Environment, Agricultural Sciences and Spatial Planning under project number: 21.4/2003-1410. The authors gratefully acknowledge financial support by the Max Planck Society. Agroscope ART thanks C. Hüglin of EMPA Materials Science and Technology, Switzerland, for providing the AiRRmonia instrument.

Edited by: J. Rinne

\section{References}

Ammann, C., Flechard, C., Fuhrer, J., and Neftel, A.: Greenhouse gas budget of intensively and extensively managed grassland, in: Land Use Systems in Grassland Dominated Regions, edited by: Lüscher, A., Jeangros, B., Kessler, W., et al., Grassland Science in Europe, vdf Hochschulverlag, Zürich, Switzerland, 9, 130132, 2004.

Ammann, C., Flechard, C. R., Leifeld, J., Neftel, A., and Fuhrer, J.: The carbon budget of newly established temperate grassland depends on management intensity, Agr. Ecosyst. Environ., 121, 5-20, 2007.

Asman, W. A. H., Sutton, M. A., and Schjorring, J. K.: Ammonia: emission, atmospheric transport and deposition, New Phytol., 139, 27-48, 1998.

Bouwman, A. F., Lee, D. S., Asman, W. A. H., Dentener, F. J., Van der Hoek, K. W., and Olivier J. G. J.: A global high resolution emission inventory for ammonia, Global Biogeochem. Cy., 11, 561-587, 1997.

Charlson, R. J., and Rodhe, H.: Factors controlling the acidity of natural rainwater, Nature, 295, 683-685, 1982.

Dasgupta, P. K.: Automated measurements of atmospheric trace gases: Diffusion based collection and analysis, in: Measurements Challenges in Atmospheric Analysis, edited by: Newman, L., Adv. Chem. Ser., 232, 41-90, 1993.

Dentener, F. J. and Crutzen P. J.: A three-dimensional model of the global ammonia cycle, J. Atmos. Chem., 19, 331-369, 1994.

Decuq, C., Loubet, B., Personne, E., Ferrara, R., Masson, S., Flura, D., and Génermont, S.: Effect of temperature on ammonia measurements by semi-permeable membrane coupled with conductivity, NitroEurope-IP Open Science Conference, Ghent, Belgium, 20-21 February 2008, p. 43, 2008.

Erisman, J. W., Otjes, R., Hensen, A., Jongejan, P., van den Bulk, P., Khlystov, A., Möls, H., and Slanina, S.: Instrument development and application in studies and monitoring of ambient ammonia, Atmos. Environ., 35, 1913-1922, 2001.
Fangmeier, A. F., Hadwiger-Fangmeier, A., Van der Eerden, L., and Jager, H. J.: Effects of atmospheric ammonia on vegetation: A review, Environ. Pollut., 86, 43-82, 1994.

Fehsenfeld, F. C., Huey, L. G., Leibrock, E., Dissly, R., Williams, E., Ryerson, T. B., Norton, R., Sueper, D. T., and Hartsell, B.: Results from an informal intercomparison of ammonia measurement techniques, J. Geophys. Res., 107(D24), 4812, doi:10.1029/2001JD001327, 2002.

Ferm, M.: Method for determination of atmospheric ammonia, Atmos. Environ., 13, 1385-1393, 1979.

Flechard, C. R., Neftel, A., Jocher, M., Ammann, C., and Fuhrer, J.: Bi-directional soil/atmosphere $\mathrm{N}_{2} \mathrm{O}$ exchange over two mown grassland systems with contrasting management practices, Global Change Biol., 11, 2114-2127, 2005.

Gall, R., Perner, D., and Ladstatter-Weissenmayer, A.: Simultaneous determination of $\mathrm{NH}_{3}, \mathrm{SO}_{2}, \mathrm{NO}$ and $\mathrm{NO}_{2}$ by direct UVabsorption in ambient air, Fresen, J. Anal. Chem., 340, 646-649, 1991.

Gang, L.: Catalytic oxidation of ammonia to nitrogen, Ph.D thesis, Technische Universiteit Eindhoven, ISBN: 90-386-2653-3, NUGI 813, 2002.

Genfa, Z., Dasgupta, P. K., and Dong, S.: Measurements of atmospheric ammonia, Environ. Sci. Technol., 23, 1467-1474, 1989.

Genfa, Z., Slanina, F., Boring, S. C. B., Jongejan, P. A. C., and Dasgupta, P. K.: Continuous wet denuder measurements of atmospheric nitric and nitrous acids during the 1999 Atlanta Supersite, Atmos. Environ., 37, 1351-1364, 2003.

Hansel, A., Jordan, A., Holzinger, R., Prazeller, P., Vogel, W., and Lindinger, W.: Proton transfer reaction mass spectrometry: Online trace gas analysis at the ppb level, Int. J. Mass Spectrom., 149-150, 609-619, 1995.

Jäggi, M., Ammann, C., Neftel A., and Fuhrer, J.: Environmental control of profiles of ozone concentration in a grassland canopy, Atmos. Environ., 40, 5496-5507, 2006.

Lindinger, W., Hansel, A., and Jordan, A.: Proton-transfer reaction mass spectrometry (PTR-MS): on-line monitoring of volatile organic compounds at pptv levels, Chem. Soc. Rev., 27, 347-375, 1998.

Mennen, M. G., van Elzakker, B. G., van Putten, E. M., Uiterwijk, J. W., Regts, T. A., van Hellenmond, J., Wyer, G. P., Otjes, R. P., Verhage, A. J. L., Wouters, L. W., Heffels, C. J. G, Römer, F. G., van den Beld, L., and Tetteroo, J. E. H.: Evaluation of automatic ammonia monitors for application in an air quality monitoring network, Atmos. Environ., 30, 3239-3256, 1996.

Milford, C., Sutton, M. A., Allen, A. G., Karlsson, A., Davison, B. M., James J. D., Rosman, K., Harrison, R. M., and Snape, J. N.: Marine and land-based influence on atmospheric ammonia and ammonium over Tenerife, Tellus Ser. B, 52, 273-289, 2000.

Mozurkewich, M.: The Dissociation-Constant of AmmoniumNitrate and Its Dependence on Temperature, Relative-Humidity and Particle-Size, Atmos. Environ. A-Gen., 27, 261-270, 1993.

Neftel, A., Flechard, C., Ammann, C., Conen, F., Emmenegger, L., and Zeyer, K.: Experimental assessment of $\mathrm{N}_{2} \mathrm{O}$ background fluxes in grassland systems, Tellus, 59B, 470-482, 2007.

Neuman, J. A., Huey, L. G., Ryerson, T. B., and Fahey, D. W.: Study of Inlet Materials for Sampling Atmospheric Nitric Acid, Environ. Sci. Technol., 33, 1133-1136, 1999.

Norman, M., Hansel, A., and Wisthaler, A.: $\mathrm{O}_{2}^{+}$as primary reagent ion in the PTR-MS instrument: Detection of gas-phase ammonia, 
Int. J. Mass Spectrom., 265, 382-387, 2007.

Nowak, J. B., Huey, L. G., Russell, A. G., Tian, D., Neuman, J. A., Orsini, D., Sjostedt, S. J., Sullivan, A. P., Tanner, D. J., Weber, R. J., Nenes, A., Edgerton, E., and Fehsenfeld, F. C.: Analysis of urban gas phase ammonia measurements from the 2002 Atlanta Aerosol Nucleation and Real-Time Characterization Experiment (ANARChE), J. Geophys. Res., 111, D17308, doi:10.1029/2006JD007113, 2006.

Nowak, J. B., Neuman, J. A., Kozai, K., Huey, L. G., Tanner, D. J, Holloway, J. S., Ryerson, T. B., Frost, G. J., McKeen, S. A., and Fehsenfeld, F. C.: A chemical ionization mass spectrometry technique for airborne measurements of ammonia, J. Geophys. Res., 112, D10S02, doi:10.1029/2006JD007589, 2007.

Otjes, R. P. and Erisman, J. W.: Haalbaarheidstudie miniaturisering ammoniak analyser (Feasibility study on the diminution of ammonia analyser), Report ECN-CX-99-015, ECN, Petten, The Netherlands (in Dutch), 1999.

Parrish, D. D. and Fehsenfeld, F. C.: Methods for gas-phase measurements of ozone, ozone precursors and aerosol precursors, Atmos. Environ., 34, 1921-1957, 2000.

Pushkarsky, M. B., Webber, M. E., Baghdassarian, O., Narasimhan, L. R., and Patel, C. K. N.: Laserbased photoacoustic ammonia sensor for industrial applications. Appl. Phys. B-lasers special issue: Trends in Laser Sources, Spectroscopic Techniques and Their Applications to Trace Gas Detection, 75, 391-396, 2002.

Shah, S. B., Grabow, G. L., and Westerman, P. W.: Ammonia absorpition of five types of flexible tubing materials, Appl. Eng. Agric., 22(6), 919-923, 2006.

Slanina, J., ten Brink, H. M., Otjes, R. P., Even, A., Jongejan, P., Khlystov, A., Waijers-Ijpelaan, A., and Hu, M.: The continuous analysis of nitrate and ammonium in aerosols by the steam jet aerosol collector (SJAC): extension and validation of the methodology, Atmos. Environ., 35, 2319-2330, 2001.

Sutton, M. A., Tang, Y. S., Miners, B., and Fowler, D.: A New Diffusion Denuder System for Long-Term, Regional Monitoring of Atmospheric Ammonia and Ammonium, Water Air Soil Poll.: Focus 1: 145-156, 2001.
Thomas, R. M., Trebs, I., Otjes, R., Jongejan, P. A. C., ten Brink, H., Philips G., Kortner, M., Meixner, F. X., and Nemitz, E.: An automated analyzer to measure surface-atmosphere exchange fluxes of water soluble inorganic aerosol compounds and reactive gases, Environ. Sci. Technol., 43(5), 1412-1418, doi:10.1021/es8019403, 2009.

Trebs, I., Meixner, F. X., Slanina J., Oties, R. P., and Andreae, M. O.: Real-time measurements of ammonia, acidic trace gases and water-soluble inorganic aerosol species at a rural site in the Amazon Basin, Atmos. Chem. Phys., 4, 967-987, 2004, http://www.atmos-chem-phys.net/4/967/2004/.

Warland, J. S., Dias, G. M., and Thurtell, G. W.: A tunable diode laser system for ammonia flux measurements over multiple plots, Environ. Pollut., 114, 215-221, 2001.

Wells, M., Choularton, T. W., and Bower, K. N.: A modeling study of the interaction of ammonia with cloud, Atmos. Environ., 32, 359-363, 1998.

Whitehead, J. D., Twigg, M., Famuali, D., Nemitz, E., Sutton, M. A., Gallager, M. W., and Fowler, D.: Evaluation of laser absorption spectroscopic techniques for eddy covariance flux measurements of ammonia, Environ. Sci. Technol., 42(6), 2041-2046, 2008.

Wiebe, H. A., Anlauf, K. G., Tuazon, E. C., Winer, A. M., Biermann, H. W., Appel, B. R., Solomon, P. A., Cass, G. R., Ellestad, T. G., Knapp, K. T., Peake, E., Spicer, C. W., and Lawson, D. R.: A Comparison of Measurements of Atmospheric Ammonia by Filter Packs, Transition-Flow Reactors, Simple and Annular Denuders and Fourier-Transform Infrared-Spectroscopy, Atmos. Environ. A-Gen., 24, 1019-1028, 1990.

Wyers, G. P., Otjes, R. P., and Slanina, J.: A continuous-flow denuder for the measurement of ambient concentration and surfaceexchange fluxes of ammonia, Atmos. Environ, 27A, 2085-2090, 1993.

Yokelson, R. J., Christian, T. J., Bertschi, I. T., and Hao, W. M.: Evaluation of adsorption effects on measurements of ammonia, acetic acid and methanol, J. Geophys. Res., 108, 4649, doi:10.1029/2003JD003549, 2003. 